Objectives: To study the subclinical inflammation in intercritical gout patients and its possible relation to the estimated size of the crystal deposition and the number of $\mathrm{CV}$ risk factors.

Methods: To analyze subclinical inflammation we performed a secretome analysis and a cytokine and adiponektine plasma levels quantification (IL-1 $\beta$, IL-18, IL-6, sIL-6R, TNF $\alpha$, CXCL-5, RANTES, leptin, resistin and adiponectin) in a cohort of gout patients. As nowadays it is not feasible to determinate the whole body deposit of MSU crystals we created three different MSU crystal deposit size patient groups using an indirect clinical and analytical classification to estimate it. Then we compared cytokine levels between healthy donors and gout patients. We also compared cytokine levels between the different crystal size deposition groups and studied its association to the number of CV risk factors.

Results: Ninety consecutive patients attending a Crystal Arthritis Unit were studied. Mean age was 68.27 (28-101) years. $81.1 \%$ were male. Clinical gout evolution was of $10.1 \pm 9.8$ years. $77.5 \%$ were on urate lowering treatment. $24 \%$ had tophaceous gout. Mean uric acid was $6.3 \pm 2.1 \mathrm{mg} / \mathrm{dl}$ with $47.1 \%$ of them being on target. Hypertension was present in $68.9 \%$, diabetes mellitus in $18.9 \%$, dislipemia in $48.9 \%, \mathrm{BMI}>30$ in $32.9 \%$, abdominal obesity in $50 \%$ and $16.1 \%$ suffered from ischemic heart disease. From the 102 molecules studied in the secretome analysis in 56 there was at least a $20 \%$ difference between donors group and any of the deposition groups. In $74 \%$ of them gout patients secreted lower levels. IL-18, sIL-6R, RANTES, leptin and adiponectin were higher in patients than in healthy donors. IL-18, sIL6-R, RANTES and CXCL5 levels were associated to the size of the crystal deposits. IL-18, sIL-6R, RANTES and leptin were higher in gout groups with CV risk factors. IL-18, sIL6-R, RANTES and leptin were higher in gout patients with no risk factors when compared to healthy donors with no risk factors. We found no differences when comparing urate lowering treated and non-treated patients.

Conclusion: Our results demonstrate that some proinflammatory cytokines and metabolic proteins are raised in intercritical gout patients. Some of them are different from the flare/inflammasome expected ones. In some cytokines this elevation is related to the size of the monosodium urate crystal deposit and/or to the number of cardiovascular risk factors. This cytokine changes could help to explain the increase of the cardiovascular events in gout patients.

Disclosure of Interests: Cesar Diaz-Torne Grant/research support from: Received a grant from Grünenthal, Maria Angels Ortiz: None declared, Sicylle Jeria Navarro: None declared, Andrea Garcia-Gullien: None declared, Lluis Sainz: None declared, Hector Corominas: None declared, Silvia Vidal: None declared

DOI: 10.1136/annrheumdis-2021-eular.1478

\section{POS0133 \\ MONOSODIUM URATE CRYSTALS REDUCE HUMAN LIGAMENT CELLS VIABILITY THROUGH INCREASE OF ROS PRODUCTION}

Y. Huang ${ }^{1}$, Y. Liu ${ }^{1}$, Q. Huang ${ }^{1}$, W. Deng ${ }^{1}$, T. W. Li ${ }^{1} .{ }^{1}$ Guangdong Second Provincial General Hospital, Department of Rheumatology and Immunology, Guangzhou, China

Background: Ligament destruction is a frequent complication of gout and is strongly associated with tophi. Ligament fibroblasts are important cellular mediators of ligament remodeling. None of study has paid attention to the effects of monosodium urate (MSU) crystals on ligament fibroblasts.

Objectives: The study aims to investigate the effects and mechanism of MSU crystals on ligament fibroblasts.

Methods: MSU crystals were added to human ligament fibroblasts(HLFs) cultures or primary ligament cells cultures. Cell counting kit-8 (CCK-8) assay, cell migration assay, Annexin V-FITC/PI assay were conducted. Reactive Oxygen Species(ROS) was tested by ROS Assay Kit.

Results: The higher concentrations of MSU crystals $(0.5-1 \mathrm{mg} / \mathrm{mL})$ reduced the viability of HLFs or primary ligament cells after $24 \mathrm{~h}$ as assessed by CCK 8 assays, with a further reduction in viability observed at the $48 \mathrm{~h}$ time point. When observed under light microscopy, HLFs cultured with MSU crystals $(0.5 \mathrm{mg} / \mathrm{mL})$ appeared unhealthy with fewer cells present. The cell migration ability of HLFs was decreased significantly on MSU crystals $(0.5 \mathrm{mg} / \mathrm{mL})$. According to the result of Annexin V-FITC/PI assay, the survival rate of HLFs on MSU crystals $(0.5 \mathrm{mg} /$ $\mathrm{mL}$ ) was lower than that of $0.25 \mathrm{mg} / \mathrm{ml}$ and $0 \mathrm{mg} / \mathrm{ml}$ at $72 \mathrm{~h}$. ROS assay results showed that the production of ROS increased as the concentrations of MSU crystals increased.
Conclusion: MSU crystals inhibit human ligament cells viability through the increase of ROS production. It may contribute to disordered ligament remodeling in gout patients with ligament destruction.

\section{REFERENCES:}

[1] Ashika Chhana, et al. Monosodium urate crystals reduce osteocyte viability and indirectly promote a shift in osteocyte function towards a proinflammatory and proresorptive state. Arthritis Res Ther. 2018, 20(1): 208.

A
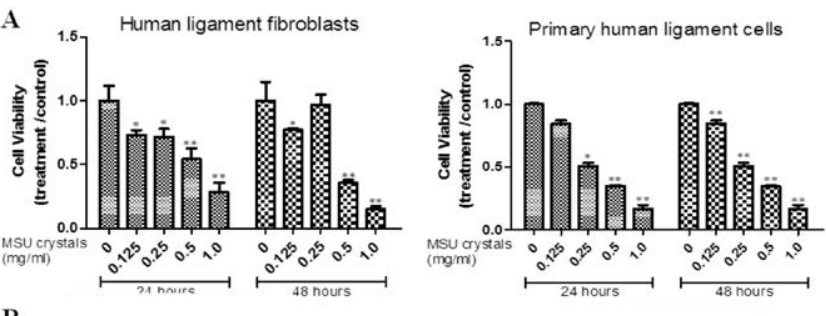

B Control
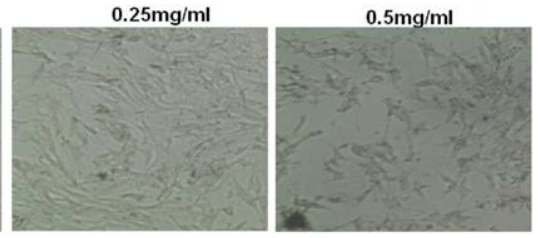

C
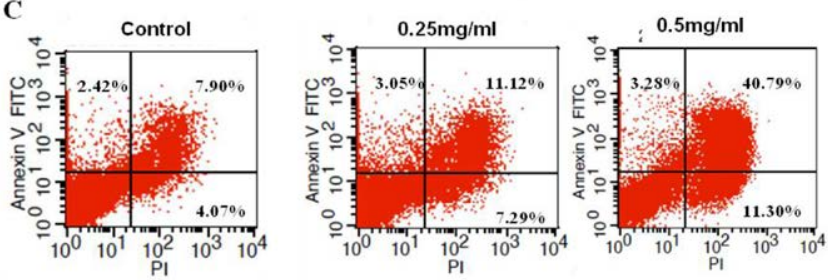

Figure 1. MSU crystals reduce human ligament fibroblasts and primary human ligament cells viability over time. A: CCK-8 assay; B: Observation of HLFs morphology; C: Annexin V-FITC/ PI assay.

Disclosure of Interests: None declared DOI: 10.1136/annrheumdis-2021-eular.2316

\section{POS0134 \\ INCREASED PREVALENCE OF LUMBAR SPINE MONOSODIUM URATE DEPOSITION AMONG GOUT PATIENTS ON DUAL-ENERGY CT}

M. Toprover ${ }^{1,2}$, M. Mechlin ${ }^{3}$, A. Slobodnick ${ }^{1}$, V. C. Pike ${ }^{1}$, C. $\mathrm{Oh}^{4}$, C. Davis ${ }^{5}$, T. Fields ${ }^{6}$, F. Becce ${ }^{7}$, M. H. Pillinger ${ }^{1,2} .{ }^{1}$ New York University Grossman School of Medicine, Medicine/Rheumatology, New York, United States of America; ${ }^{2}$ New York Harbor Health Care System, US Department of Veterans Affairs, Medicine/Rheumatology, New York, United States of America; ${ }^{3}$ New York University Grossman School of Medicine, Musculoskeletal Radiology, New York, United States of America; ${ }^{4}$ NYU Grossman School of Medicine, Biostatistics, New York, United States of America; ${ }^{5}$ NYU Grossman School of Medicine, Medicine/Rheumatology, New York, United States of America; ${ }^{6}$ The Hospital for Special Surgery, Rheumatology, New York, United States of America; ${ }^{7}$ Lausanne University Hospital, Radiology and Interventional Radiology, Lausanne, United States of America

Background: Gout affecting the spine is reported as a rare event presenting with neuropathy, spinal compression and acute back pain (1). Cases are often diagnosed by tissue confirmation of monosodium urate (MSU) deposition. The frequency of gout involving the spine asymptomatically or with milder, non-specific symptoms is likely higher than reported.

Objectives: Using dual-energy CT (DECT), we are determining prevalence/ extent of MSU deposition in the lumbosacral spines of patients with gout and tophaceous gout, compared to non-gout controls. 